\title{
A transaction cost approach to climate adaptation: Insights from Coase, Ostrom and Williamson and evidence from the 400-year old zangjeras
}

\author{
Eduardo Araral \\ National University of Singapore, Lee Kuan Yew School of Public Policy, 469C Bukit Timah Road, Singapore, Singapore
}

\section{A R T I C L E I N F O}

\section{Keywords:}

Coase

Ostrom

Williamson

Climate adaptation

Transaction cost

Collective action

Local commons

Water resources management Irrigation

\begin{abstract}
A B S T R A C T
I argue in this paper that transaction cost is central to the analytics of climate adaptation in the local commons. I illustrate this by bringing together insights from Coase on tradability of property rights, Ostrom on institutional design principles for long lived commons and Williamson on transaction cost and governance mechanisms. I call this the COW model on the analytics of climate adaptation, which I illustrate using grounded theory in the case of the 400-year old zangjera irrigation societies in Northern Philippines. The zangjeras are highly vulnerable to climatic risks but has successfully managed to adapt steadily overtime. I argue that their ability to adapt is a function of transaction cost which is associated with some ingenious principles of institutional design such as: (1) clear allocation and tradability of rights and obligations; (2) fairness in the allocation of risks, costs and benefits; (3) reliance on prices and incentives as adaptation mechanisms; (4) adaptive efficiency, i.e. maximization of welfare at least adaptation cost; (5) reliable enforcement mechanisms; and (6) a polycentric structure of governance. I conclude that the COW model can provide a useful foundation for the analytics of climate adaptation.
\end{abstract}

(C) 2012 Elsevier Ltd. All rights reserved.

\section{Introduction}

The debate on climate change has been shifting overtime from evidence to mitigation to assessment of impacts and more recently towards adaptation (Kundzewicz et al., 2007; Barnett et al., 2004). The climate adaptation literature, however, is still at its infancy as can be gleaned from the range of outstanding theoretical, empirical and methodological issues. First, the empirical links between adaption, local institutions and climatic risks are often tenuous. On one hand, climate scientists propose adaptation options based on future climate scenarios that rely on low resolution General Circulation Models (GCMs) but often ignore social science considerations in their models, for example Kundzewicz et al. (2007); Lehner et al. (2005) and Arnell (2004). As a result, these GCM models have resulted into recommendations biased towards engineering approaches to climate mitigation and do not recognize social mechanisms of adaptation. Social scientists on the other hand study adaption but do not integrate the work of climate scientists. For instance, majority of the 118 case studies in the UNFCC database on adaptation imply or assert but do not demonstrate how variations in weather patterns are linked to adaptation strategies. Other scholars, for instance, Orlove (2005) and Janssen (2011) have been advocating for a more multidisciplinary approach to the study of adaptation.

Second, most economists, for example Stern (2007), have widely debated which policy instruments - taxes, markets, property rights and regulation - can best mitigate climate change but little research has been done which instruments best facilitate adaptation. Some scholars, for example Agrawal

E-mail address: ekararal@hotmail.com 
(2007), suggest that market exchange is one of the most versatile forms of adaptation because it can substitute for other forms such a mobility, storage, diversification, and communal pooling. However, little research has been done demonstrating its effectiveness, efficiency, equity and sustainability as an adaptation mechanism for rural households. The literature is also often not clear what types of markets, i.e. market for labor, land, water, spot markets, long term markets, cash or barter markets, among others, facilitate adaptation. With the exception of the market for climate related insurance, it is often not clear how markets serve as a mechanism of adaptation.

Third, conventional wisdom suggests that assignment of clear and enforceable property rights can help facilitate the functioning of markets. However, while the allocation of property rights with trading - the Coasian solution - is central to proposals for climate change mitigation, little is known if it can be applied to adaptation. Coase himself has noted how the Coasian solution has "often been cited but seldom used."1 Indeed, documentation of successful Coasian solution is rare in the adaptation literature.

Instead, the literature relies mostly on inductive reasoning on what constitutes adaptive management, for example PahlWostl (2007).

Finally, while local institutions for collective action are also widely regarded as an important mechanism for adaptation, apart from markets, scholars have yet to adequately address the question what types of local institutions facilitate robust adaption to climate risk. Some scholars, for example Agrawal (2002), Wade (1989), Ostrom (1990), Baland and Plateau (1996), Ribot (2002), Araral (2009) have identified at least 20 factors they suggest could facilitate collective action in the commons. While this is a useful starting point, there is scant research that links this corpus of knowledge to the climate adaptation literature. Moreover, the treatment of adaptation institutions in the literature tend to be mechanistic - public, private, civic institutions, public or common property - and thus do not provide much insight into the effectiveness, efficiency and robustness of their design. Crucially, the literature often assumes that local institutions are exogenous when they could have evolved as an adaptation mechanism themselves. A promising line of work on risk and vulnerability from a resilience perspective is that of Haque and Etkin (2012) and Berkes (2012) and from local institutions perspective, Orlove (2005) and Agrawal (2007).

In this paper, I argue that transaction cost provides an analytic foundation to the study of climate adaptation in the local commons, which is an emerging field of study. I illustrate this by bringing together insights from Coase on tradability of property rights, Ostrom on institutional design principles for long lived commons and Williamson on transaction cost and governance mechanisms. I call this the COW model to the analytics of climate adaptation, which I illustrate using grounded theory in the case of the 400-year old zangjera irrigation societies in Northern Philippines. The zangjeras are highly vulnerable to climatic risks but has managed to adapt steadily overtime. I argue that their ability to adapt is a

\footnotetext{
${ }^{1}$ Personal conversation with Ronald Coase, March 2008, Chicago.
}

function of transaction cost which is associated with some ingenious principles of institutional design. I argue that the COW model can provide a useful foundation to the analytics of climate adaptation.

The next section provides an overview of the COW approach to the analytics of climate adaptation followed by a description of the data and methodology and an in-depth discussion of key findings in the case study. The concluding section outlines the implications of the study.

\section{Adaptation analytics and the cow approach}

In this section, I will first explore the analytics of climate adaptation. I will then elaborate what is the COW approach and why and how it is useful for the analytics of adaptation. In the next section, I will apply this analytics in the case of the Zangjera.

\subsection{Transaction cost and adaptation analytics}

Climate change, particularly in the commons, is expected to lead to greater uncertainties and variability in temperatures and the associated problems of droughts and flooding. Households whose livelihoods are affected by these changes would have to learn how to adapt to this variability. Adaptation can take several forms. For instance farmers can switch to different crops depending on the availability of water and agronomic suitability. In times of droughts, farmers can mobilize labor and capital to devise storage devices. They can also agree among themselves water allocation mechanisms including crop rotation. They can also opt out and sell their farms and move to cities and become laborers. They can take out loans to tide and shift to a different form of livelihood. Farmers organizations can also undertake adaptation measures collectively, for instance engineering measures such as canal lining to minimize water transmission loses.

All of these adaptation mechanisms involve varying degrees of transaction costs. These include, for example, mobilizing labor to build or fix storage facilities in times of flooding to settling disagreements on right of way in building canals, water allocation and crop rotation schemes at times of droughts to organizing how to supply, monitor and enforce rules as part of the adaptation process.

Indeed, scholars generally agree that local institutions along with other factors such as the level of education, wealth, resource endowments, social organization and local knowledge - affects the ability of poor households in adapting to climatic risks. Agrawal (2007) describes at least three transmission channels. First, they structure environmental risks and variability and thereby the nature of climate impacts and vulnerabilities. Second, institutions create the incentive framework within which outcomes of individual and collective action unfold. Third, institutions serve as the mechanisms through which external interventions reinforce or undermine existing adaptation practices.

In Mexico, Eakin (2005) finds that institutional connections provide households and communities greater flexibility in their choice of diversification and adaptation strategies. In 
Mongolia, risk pooling through market-based insurance is being tested as an adaptation measure to assist pastoralists affected by extreme weather conditions. In Peru, finds that poor tribal households are adapting to climate change by diversifying sources of livelihood, for instance adopting new maize varieties, shifting from agro-pastoralism to wage labor in tourism, mining and construction projects. In the Philippines, Lasco et al. (2006) identified 20 intermediary adaptation roles of local institutions. For adaptation in agriculture more generally, see Howden et al. (2007).

Perhaps the most useful source of case materials on climate adaptation and local institutions is the UNFCC database from 46 developing countries, which has a total of 118 case studies. Of the 118 cases, 61 are about arid areas and 36 on coastal zones and the rest about irrigation and highland areas. An interesting feature of the database is that most of the case studies involve informal and self-reliant local institutions. To make sense of these diverse range of adaptations, Agrawal suggests five analytical categories of adaptation responses, namely mobility, which helps address risks across space, storage (time), diversification (asset classes), communal pooling (across households), and market exchange - which can substitute for the above four classes of risk mitigation when households and communities have access to markets. Out of 97 case studies in arid and coastal zones from the UNFCC database, 77 cases are related to diversification, communal pooling and market exchange. The effectiveness of these strategies, Agrawal argues, is in part a function of the social and institutional contexts in which they are pursued.

\subsection{The COW model}

This paper brings together the core insights from the work of economics Nobel Laureates Coase, Ostrom and Williamson, which I refer to as the COW approach to the analytics of climate adaptation. None of them were particularly concerned with the issue of climate adaptation but as this paper will argue and show, collectively their core ideas can be extended to the analytics of climate adaptation. Fig. 1 provides a schematic view of the model.

Coase (1960) was concerned with the efficiency implications of the initial allocation of property rights. He argued in what is now known as the Coase theorem that the initial allocation of rights has no effects on efficiency if transaction costs (TC) are low which will allow the parties to trade. Coase, however, stopped short of explaining how TC can be kept to a minimum. Following Coase, Williamson (1999) showed that TC among business firms would vary depending on their governance mechanism, i.e. through markets (contracting) or hierarchies (firms) or hybrids. The choice of governance mechanisms in turn depends on the hazards or risks of opportunism faced by the firm in contracting. In cases where hazards are high, hierarchies would dominate while in cases where hazards are low, contracting will be the dominant governance mechanism. Williamson's main contribution therefore is to show how transaction costs would vary in terms of the governance mechanisms.

Ostrom (1990) on the other hand described the governance mechanisms associated with long-lived common pool

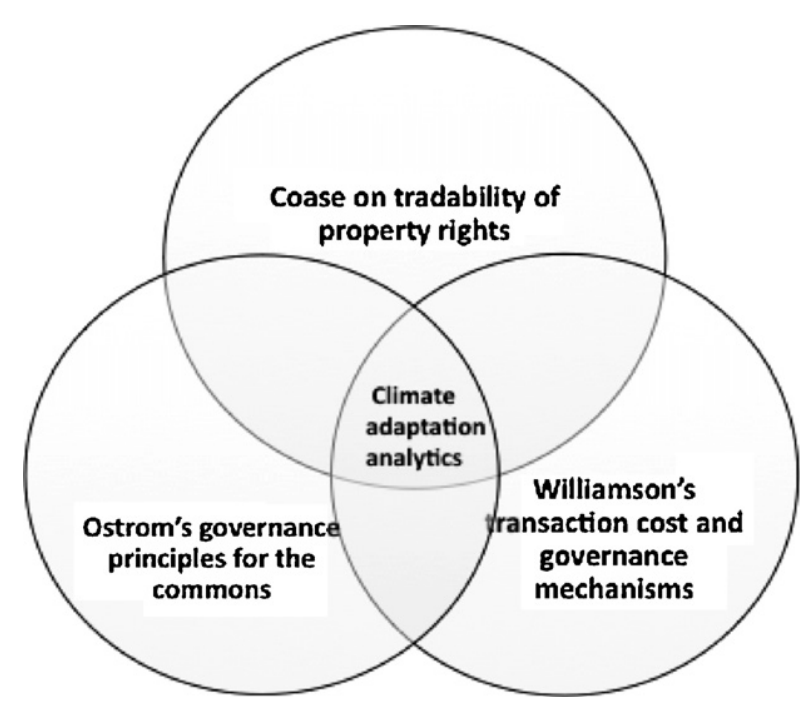

Fig. 1 - The COW analytics of climate adaptation.

resources such as forests, fisheries and irrigations. Ostrom finds that commons which have survived for long periods of time - contrary to conventional wisdom such as tragedy of the commons and the prisoner's dilemma - are characterized by seven principles of institutional design, namely: (1) clearly defined boundaries of the commons; (2) rules regarding the appropriation and provision of common resources that are adapted to local conditions; (3) collective-choice arrangements that allow most resource appropriators to participate in the decision-making process; (4) effective monitoring by monitors who are part of or accountable to the appropriators; (5) a scale of graduated sanctions for resource appropriators who violate community rules; (6) mechanisms of conflict resolution that are cheap and of easy access; (7) self-determination of the community recognized by higher-level authorities; and (8) in the case of larger common-pool resources, organization in the form of multiple layers of nested enterprises, with small local CPRs at the base level.

From a TC perspective, Ostrom's design principles collectively suggest that robust common pool resources are characterized by low levels of transaction costs because of their clearly defined and enforceable property rights, fairness in the allocation of costs and benefits and high levels of self regulation. These principles, however, do not explicitly incorporate the Coase theorem - tradability of rights - in the commons apart from indicating the importance of clear allocation and enforceability of rights.

Individually, these ideas - tradable property rights (Coase), institutional design principles (Ostrom), and transaction costs (Williamson) - have not been extended to the analytics of climate adaptation. For instance, Williamson's work was mainly applied to business firms. While Ostrom's work is closely related to the commons, she did not particularly examine the analytics of climate adaptation. The Coasian approach is well known in the climate change mitigation literature - in the form of cap and trade regimes - but is hardly debated in the adaptation literature. This is unfortunate because water rights will become more and more crucial as water resources become scarce due to climate change and 
increasing demand. This problem is particularly acute in developing countries where rule of law is unreliable and water rights allocation is often unclear, uncertain and unaccountable. This is complicated by the fact that water rights comprise a bundle of rights and is dynamic, complex, localized, and politically salient.

Collectively, however, these ideas can provide the foundation for the analytics of climate adaptation. The core argument of the paper can thus be summarized as follows.

First, climate adaptation in the local commons involves significant transaction costs - which I refer to as adaptation transaction costs (ATCs) - in terms of mobilizing labor to adapt to challenges of droughts and flooding, resolving disputes in water allocation in times of droughts as well as supplying, monitoring and enforcing rules associated with adaptation. ATC therefore lie at the heart of the analytics of climate adaptation in the local commons and minimizing ATC holds the key to climate adaptation.

Second, climate change implies increasing water scarcity and competition. In local commons, water rights serve as the mechanism to allocate scarce water resources. If water rights, therefore, can be traded with minimum transaction costs, then appropriators of water resources can trade among themselves and adapt to climate change accordingly.

Third and finally, water rights are only valuable if they can be traded but they can only be traded if they are protected which in turn requires low cost mechanisms of enforcement such as a high degree of self-governance and regulation, the sort of principles propounded on by Ostrom.

\section{Case study and methodology}

I employ grounded theory as my analytic approach, a method in social science that relies on inductive reasoning using a case study. Grounded theory is appropriate given my goal of understanding the design and functioning of market and collective action mechanisms to climate adaptation. Grounded theory has been applied by social ecologists, for example Lejano and Ingram (2009), to study collective action in a variety of settings, from environment and natural resource issues, health and disaster management. For more on grounded theory, see Glaser and Strauss (1967).

In choosing a suitable case study, three criteria were considered. First, it should allow for an assessment of past, current and future climate change vulnerabilities. Second, it should provide valuable insights in the application of the COW approach to climate adaptation. Finally, the case study should allow for comparison of adaptations overtime to enable an assessment of its outcomes.

The zangjera irrigation systems in the Ilocos Provinces in Northern Philippines meet these three criteria. First, they have been around for 400 years and are still functioning today despite significant vulnerabilities they face such as increasingly frequent and intense typhoons and rainfall, increasing frequency of extreme temperature, an unsteady, unpredictable and destructive river system as well as intense population pressures and land shortage. Rainfall and typhoon data dating back some 60 years ago are available to allow for an assessment of how adaptation strategies have evolved overtime. Equally important, provincial level projections about rainfall, typhoon intensity and temperatures for the next 50 years are also available.

Second, in addition to climate data, the availability of historical and archival records makes it possible to study in depth the Coasian solution and allow for an assessment of adaptation measures and their effectiveness, efficiency and equity overtime. For this purpose, I chose the Vintar-Bacarra Zangjera irrigation system because it has been the subject of an intensive case study by Siy (1980) in the late 1970s with documentation dating back to the late 1800s.

Data collection involved a series of fieldwork undertaken from May to August 2008. It involved key informant interviews and focus group discussion with farmer leaders and personnel of the government irrigation agency, walkabouts in the zangjera farms, ground photo-documentation, use of aerial photos from Google Earth, archival research of demographic, engineering, demographic and climate patterns as well organizational records of the zangjera. Climate data (temperature, typhoons, rainfall intensity, frequency and projections) were obtained from official records of the Philippine Atmospheric, Geophysical and Astronomical Services Administration (PAGASA, 2011).

\section{The zangjeras case study}

Zangjera is a Spanish term referring to a cooperative irrigation society found only in the Ilocos Provinces in Northern Philippines. The population belongs to the Ilocano ethno linguistic group and the current farmers were descendants of the zangjera pioneers.

The region is located along a narrow strip of land squeezed between the Cordillera mountain range on the east and the South China Sea to the west (Fig. 2). Spanish records indicate that the zangjeras have been around since the early 16th century. As of 2008, there were some 686 zangjeras in the Ilocos Provinces with an average of 41 hectares each in service area. The early emergence of these irrigation societies in the Ilocos Region was explained by Siy (1980) in terms of the dynamics of land and population: in conditions where there is surplus labor and land is scarce and as land values rise relative to labor costs, technological choices are drawn towards those which are land saving or labor intensive. Only irrigated farming can produce enough food to support a large population and the zangjeras emerged because of the need to mobilize labor. The Ilocos Provinces meet these conditions, being one of the most densely populated regions in the Philippines and with a very limited arable land area. As a result, three fourths of all arable lands are under 0.3 ha compared with the national average of $1.45 \mathrm{ha}$.

The focus of my study is the Vintar-Bacarra (VIBA) Federation of Zangjeras. VIBA consists of nine zangjeras namely San Jose, Cabaroan, San Juan, Sinigpit, San Pedro, Collibeng, Surgui, Sto. Rosario and Nibinib. The profile of each of these zangjeras is summarized in Table 1. A notable change in the last 30 years is the significant increase in the number of members of the zangjera from 431 to 630 and almost double since their founding. In contrast, there was 

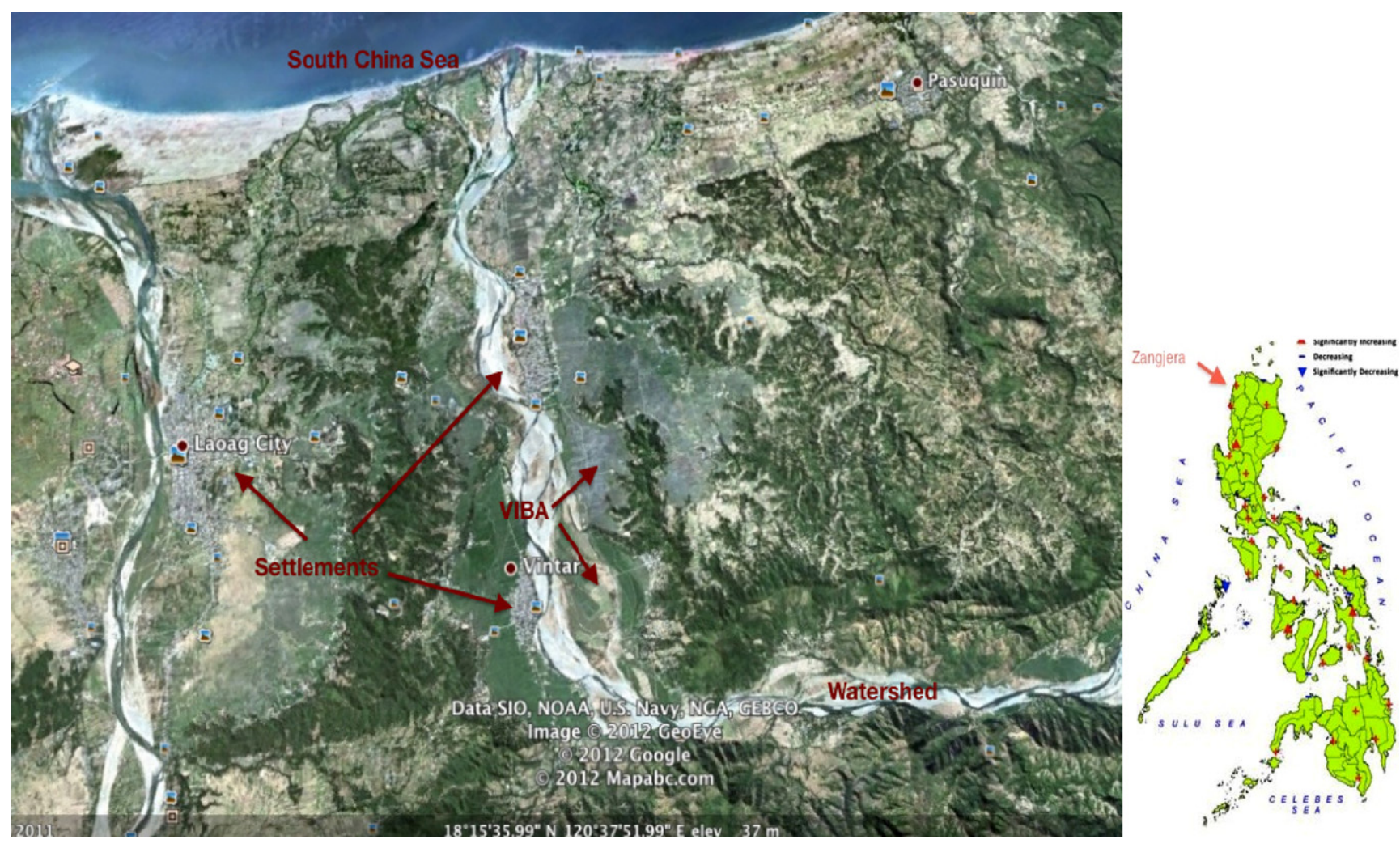

Fig. 2 - The study site: Bacarra-Vintar Riverbasin. Source: Google Earth.

not a commensurate increase in the size of the irrigable area over the same period.

The need for collective action and thus the need for VIBA came about for two reasons. The first is the need for a large pool of labor to regularly build, maintain and rebuild the brush dam in a constantly changing river course. A permanent concrete dam is not feasible in the Bacarra-Vintar River given its breadth, the frequency of destructive flooding and the size of the farms to be irrigated. The only alternative for farmers is to build a temporary brush dam, which requires substantial amounts of labor that none of the individual zangjeras could provide. It made sense for the individual zangjeras, therefore, to form a federation to more easily mobilize labor for the brush dam.

The second reason is to deal with the numerous problems of right of way for the irrigation canal. The gains from having the brush dam - more water - would only be realized if canals are constructed to distribute the water from the dam. Doing so, however, requires obtaining right of way consent from numerous farmers. None of the individual zangjeras could solve this problem on their own and therefore it made sense for them to federate in a larger scale.

\begin{tabular}{|c|c|c|c|c|c|c|c|c|c|}
\hline $\begin{array}{l}\text { Zangjera } \\
\text { name }\end{array}$ & $\begin{array}{l}\text { Joined } \\
\text { Fed'n } \\
\text { (year) }\end{array}$ & $\begin{array}{l}\text { Location } \\
\text { from } \\
\text { intake }\end{array}$ & $\begin{array}{c}\text { Farm ditch } \\
\text { density } \\
(\mathrm{m} / \mathrm{ha})\end{array}$ & $\begin{array}{c}\text { Size of } \\
\text { irrigable } \\
\text { area (ha) }\end{array}$ & $\begin{array}{l}\text { Number of } \\
\text { work groups } \\
\text { (1980) }\end{array}$ & $\begin{array}{l}\text { Member/work } \\
\text { group } \\
\text { (1980) }\end{array}$ & $\begin{array}{l}\text { Number } \\
\text { founding } \\
\text { members }\end{array}$ & $\begin{array}{c}\text { Number } \\
\text { member } \\
1980\end{array}$ & $\begin{array}{c}\text { Number } \\
\text { member } \\
2008\end{array}$ \\
\hline San Jose & 1946 & Upstream & 141 & 21.6 & 5 & 13 & 26 & 49 & 64 \\
\hline Cabaroan & 1946 & Upstream & 114 & 32.2 & 7 & 5 & 36 & 60 & 93 \\
\hline San Juan & 1952 & Midstream & 86 & 70.8 & 7 & 7 & 60 & 73 & 89 \\
\hline Sinigpit & $1950 \mathrm{~s}$ & Midstream & 86 & 30.7 & 6 & 6 & 30 & 30 & 54 \\
\hline San Pedro & 1930 & Midstream & 171 & 14.2 & 5 & 5 & 25 & 26 & 53 \\
\hline Collibeng & $1950 s$ & Tail end & 93 & 17.5 & 8 & 5 & 40 & 40 & 63 \\
\hline Surgui & $1900 s$ & Tail end & 60 & 135 & 4 & 20 & 50 & 64 & 88 \\
\hline St. Rosario & $1900 s$ & Tail end & 54 & 140 & 3 & 25 & 33 & 69 & 84 \\
\hline Nibinib & 1906 & Tail end & 57 & 43 & 2 & 8 & 17 & 20 & 42 \\
\hline Total & & & & & & & 317 & 431 & 630 \\
\hline
\end{tabular}

Source: Siy (1980); field work (2008) and NIA (2008). 


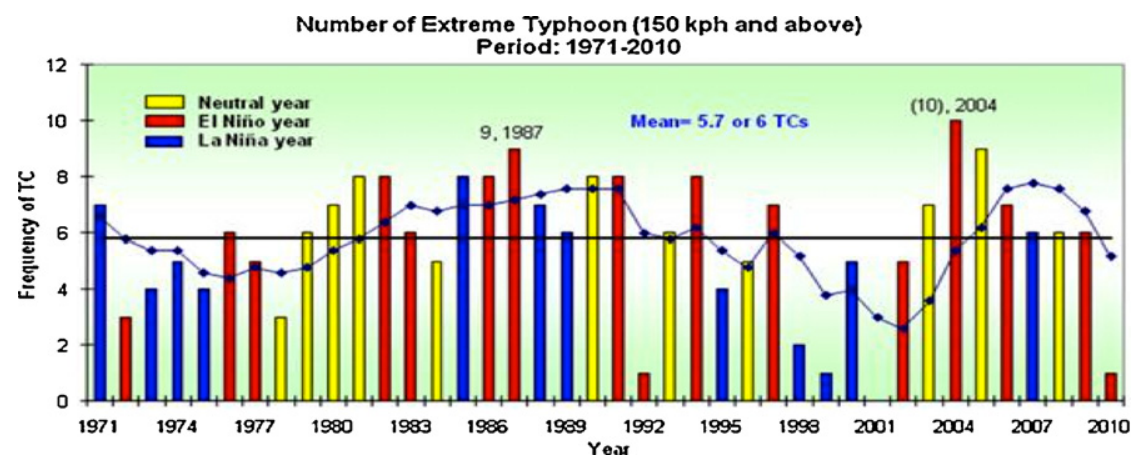

Fig. 3 - Trend analysis of extreme typhoons (150 kph and above) in Northern Philippines.

Source: PAGASA (2011).

\subsection{Vulnerabilities}

The VIBA zangjera, like most zangjeras in the region, has been persistently exposed to a wide range of vulnerabilities overtime. These include frequent and intense typhoons and flooding, unsteady, unpredictable and destructive river coupled with increasing population pressures and land scarcity. As the case study will show, the Coasian solution of tradable rights was developed by the zangjera as an adaptive response to these persistent vulnerabilities.

\subsubsection{Frequent and extreme typhoons}

A major vulnerability faced by the zangjeras is the increasingly frequent and extreme typhoons and the associated flooding that regularly afflicts the Ilocos Region.

For instance, from 1948 to 2010, the Philippines experienced an average of 20 tropical cyclones a year with a minimum of 12 and a high of 33. On average, there were 6 extreme cyclones (at least $150 \mathrm{kph}$ ) a year from 1971 to 2010 with as high as 10 in a single year (2010) (Fig. 3). Three out of four of these cyclones would hit the main island of Luzon where the zangjeras are located in the northern provinces. In the last 40 years, 28 years saw alternate patterns of El Nino and La Nina indicating the vulnerabilities of the zangjera to climate change. Indeed, historical data on rainfall patterns in the zangjeras from 1971 to 2010 shows some extreme seasonal pattern. From December to February, rainfall in Ilocos Norte, where VIBA zangjera is found, averaged $49.8 \mathrm{~mm}$ during the dry season but jumps 22 times to $1106 \mathrm{~mm}$ during the wet season from June to August. From 2006 to 2035, this is projected to further increase to $1305 \mathrm{~mm}$ or an $18 \%$ increase and a further $20.9 \%$ increase by 2050 (PAGASA, 2011).
Studies also show an increasing trend in extreme daily rainfall intensity and frequency in the Ilocos Provinces where the zangjeras are found (Table 2). For instance, the number of days when temperatures are at least $35^{\circ}$ is projected to double in the next 30 years compared with the period 1971-2000 and will quadruple by 2065. Furthermore, the number of days with rainfall exceeding $300 \mathrm{~mm}$ will increase fivefold in 20 years.

\subsubsection{Unpredictable and destructive river}

Frequent and extreme typhoons plus the geography of the region - a vast $\left(3600 \mathrm{~km}^{2}\right)$ drainage, steep mountain slopes which abruptly converges in the narrow $(3 \mathrm{~km})$ and flat plains of the Ilocos Region before draining in the South China Sea (see Fig. 1) - have created an unsteady, unpredictable and destructive Vintar-Bacarra River, the source of the VIBA irrigation system.

Because of this geography, the river constantly shifts course making the task of constructing and maintaining a brush dam and controlling water very difficult for the farmers. A typical brush dam in the zangjera-made up entirely of sand, bamboo, banana leaves and rocks - spans over $100 \mathrm{~m}$ long across the entire breadth of the river. The regular shifting of the river has also led to the regular destruction of farmlands adjacent to its banks. Because of the need to continuously construct and maintain the brush dam, flexibility in labor supply has become a paramount concern for the zangjera, which in turn has created the necessity to adapt ingenious mechanisms to solve this problem.

In addition, during the lean and dry months of JanuaryApril, water is scarce in the zangjera. Time series records from the local weather station shows that since 1950, the average rainfall in the Province during the dry months was a meager

Table 2 - Total frequency of extreme events in 2020 and 2050 under medium-range emission scenario in provinces in zangjera study site (Ilocos Norte).

\begin{tabular}{|c|c|c|c|c|c|c|c|c|c|c|}
\hline \multirow[t]{2}{*}{ Provinces } & \multirow[t]{2}{*}{ Stations } & \multicolumn{3}{|c|}{ No. of days $w / T_{\max }>35^{\circ} \mathrm{C}$} & \multicolumn{3}{|c|}{ No. of dry days } & \multicolumn{3}{|c|}{$\begin{array}{c}\text { No. of days } \\
\text { w/rainfall }>300 \mathrm{~mm}\end{array}$} \\
\hline & & OBS (1971-2000) & 2020 & 2050 & OBS & 2020 & 2050 & OBS & 2020 & 2050 \\
\hline Ilocos Norte & Laoag & 801 & 1677 & 3157 & 9015 & 7391 & 7425 & 4 & 19 & 10 \\
\hline Ilocos Sur & Vigan & 110 & 130 & 627 & 8728 & 8105 & 7939 & 1 & 17 & 6 \\
\hline Pangasinan & Dagupan & 1280 & 2265 & 3728 & 8303 & 6443 & 6419 & 2 & 13 & 20 \\
\hline
\end{tabular}


$48 \mathrm{~mm}$. In contrast, during the wet/typhoon season of JuneSeptember, the average rainfall was around $1100 \mathrm{~mm}$. Consequently, during the dry months, the availability of water among the zangjeras is highly variable with the upstream areas consistently receiving adequate water compared with the downstream. Not surprisingly, during the dry season, only farms in the upstream are irrigated and planted with rice. In the dry sections of the zangjeras downstream, farmers adapt by shifting to crops that are not as water dependent such as maize, onions and other high value crops.

\subsubsection{Other types of vulnerabilities}

Climate change induced vulnerabilities in the zangjeras are compounded by a host of interrelated economic, demographic, organizational, social and agriculture related factors. For instance, increasing population pressure is closely related to increasing resource (land, water) scarcity and the ensuing problem of land fragmentation, which could threaten the organizational stability of the zangjera and could result into social conflicts. Farming has its own inherent vulnerabilities pests, poor soil condition, vulnerabilities in factor prices, etc. In the sections that follow, I further elaborate how these vulnerabilities compound climate induced vulnerabilities and show how and why adaptation mechanisms evolved.

\section{Adaptation mechanisms}

In this section, I will explain in depth the adaptation mechanisms adopted by the VIBA zangjera to these climate induced vulnerabilities as compounded by economic, social, demographic and agriculture factors. These mechanisms include (1) clear assignment of property rights; (2) fairness and legitimacy; (3) adaptive efficiency; (4) reliable enforcement mechanisms; and (5) polycentricity. I argue that these forms of adaptation to climatic risks are not fundamentally different from many forms of adaptation in the commons literature, for example adaptive co-management, adaptive governance, community-based adaptations and the like.

\subsection{Clear property rights}

The Coasian solution to adaptation as developed by the zangjera takes the form of the tradable atar or membership share, which represents the rights and obligations of zangjera members to scarce land, labor and water resources. Siy (1980) and Coward (1979) described its features as follows: First, an original member who contributed to the establishment of the zangjera is issued one full share, which represents a right to cultivate a share of the irrigable land developed by the zangjera. The idea is similar to ownership of shares in a listed company and is transferable and the market determines the price.

Second, the atar also represents the obligations of the member to contribute labor and materials to operate and maintain the irrigation system. According to Siy (1980), the basic rule is that each atar holder is required to provide oneperson day of labor during each work session, i.e. if there are ten atar shares, there should also be 10 individuals during each work session. Over the last 400 years, the atar system has evolved along the principles of flexibility, fairness and legitimacy, adaptive efficiency and polycentricity. Clear assignment of property rights is the first design principle suggested by Ostrom as key to robust institutions governing the commons.

\subsection{Fairness and legitimacy}

The second principle of the atar is fairness and legitimacy. The atar system was designed to provide for a consistently fair allocation of risks, costs and benefits among members overtime (Coward, 1979). Table 3 shows the roughly proportional and equitable distribution of costs and benefits (columns 2 and 3) among different zangjeras in 2007. Furthermore, when the zangjera was originally formed, the parcels of land of the founding members were distributed such that some parcels were located upstream, some midstream while others are located downstream (Siy, 1980).

This way, when water is only available upstream during the dry months, the costs and benefits are fairly distributed among the members. This also gives everyone an incentive to more efficiently utilize water to ensure that their parcels at the tail end of the system are irrigated. Likewise, the distribution of fertile and less fertile parts of the farm is also made equitable with this formula of rights allocation. Furthermore, leaders of the zangjera have their parcels of land located at the tail end of the system so that they have incentives to ensure that everyone gets their share before the leader does. Finally, if

Table 3 - Equitable distribution of costs and benefits (2007).

\begin{tabular}{lcccc} 
Zangjera name & $\begin{array}{c}\text { Number of } \\
\text { atar shares }\end{array}$ & $\begin{array}{c}\text { Percent share of } \\
\text { total costs contributed } \\
\text { (labor and materials) }\end{array}$ & $\begin{array}{c}\text { Percent share of } \\
\text { benefits received } \\
\text { (water supply) }\end{array}$ & $\begin{array}{c}\text { Percent share of } \\
\text { total land area } \\
\text { irrigated }\end{array}$ \\
\hline San Jose & 26 & 8 & 8 & 4 \\
Cabaroan & 36 & 11 & 8 & 6 \\
San Juan & 60 & 19 & 29 & 14 \\
Sinigpit & 30 & 10 & 9 & 6 \\
San Pedro & 25 & 8 & 6 & 3 \\
Collibeng & 40 & 13 & 20 & 6 \\
Surgui & 50 & 16 & 6 & 27 \\
Sto Rosario & 33 & 10 & 3 & 9 \\
Nibinib & 17 & 5 & & 9 \\
\hline Source
\end{tabular}

Source: VIBA zangjera secretary's record (2007) and Siy (1980). 


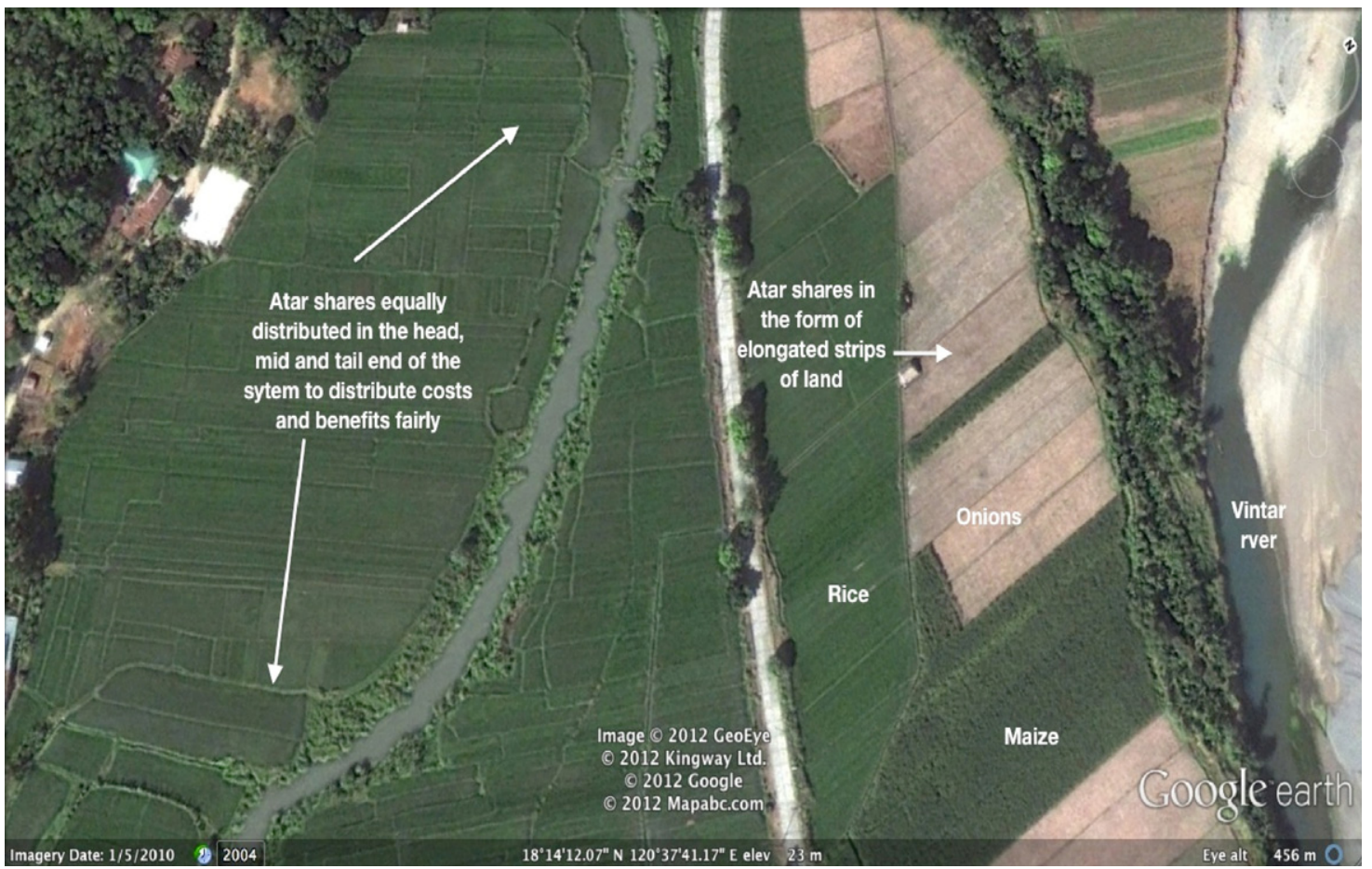

Fig. 4 - Equitable distribution of land parcels through atar membership shares. Source: Google Earth 2012.

there is not enough water for the whole system, the zangjera may decide not to irrigate particular blocks such that the farm size of all farmers are reduced proportionately since all will have parcels of land in that block (Coward, 1979). This manner of allocating land and water rights has resulted in aligning individual incentives with collective objectives such that the maximization of individual gains is contingent on the achievement of collective goals (Siy, 1980).

As a result, the atar system has been relatively successful overtime in maintaining fairness in the distribution of the costs, benefits and risks of farming among members of the zangjera. This has in turn provided a strong and sustained basis for the evolution of social capital needed to maintain the legitimacy and stability of social order among the zangjeras for over 400 years now. Fairness and legitimacy is one of the key institutional design features identified by Ostrom that characterize robust institutions for collective action.

\subsection{Adaptive efficiency}

I refer to the third principle of the atar as adaptive efficiency, i.e. maximizing welfare by reducing the costs of adaptation. There are two mechanisms for how it works. First, while the number of atar shares is fixed, its valuation can be changed in response to changes in the zangjera in a way that is fair to all atar shareholders. For instance, if a brush dam breaks down after a typhoon, the cost of additional labor and materials can be equally distributed amongst the zangjera members without the need to negotiate the cost allocation. Flexibility in valuation allows the zangjera to easily mobilize labor and materials at a relatively low cost to mitigate the damage from floods or droughts.
Second, adaptive efficiency is facilitated in the way the parcels of farmlands were configured. The way it works is as follows: atar shares in the zangjera are allocated in terms of parcels of long strips of land perpendicular to the water source (see Fig. 4). As Siy (1980) notes, this system was designed to reduce transaction cost for the farmer in securing and controlling water. Likewise, and more importantly, it was designed to give them more freedom to select cropping patterns or schedules which suits his own capabilities and needs without having to conform to decisions of neighboring farmers since water does not have to flow from those parcels into his own. As a result, at any given time, the zangjeras can afford to have a diverse array of crops in different stages of growth as well as flooded parcels next to unflooded fields.

Furthermore, parcels of land located at the bank of waterways, which had higher risks of suffering from flooding are arranged perpendicular to the flow of the river for two reasons. First, this allows for a more efficient use of water especially during times of scarcity, which allows excess water to be drained back at the source and to serve other farmers downstream. Second, the risks and costs of flooding will likely be shared by the entire membership of the zangjera rather than a few individuals.

This ingenious configuration of land parcels and the distribution of atar shares allow farmers to diversify their risks from pests, flooding, drought, prices, soil quality and hence make them highly adaptive to vulnerabilities. In essence, this mechanism helps maximize welfare (Pareto efficient) by reducing the costs of adaptation. I call this adaptive efficiency, which I suggest can be used as a metric to assess climate change adaptation measures. 


\subsection{Reliable enforcement mechanisms}

The Coasian solution is not sufficient by itself to solve the problem of increasing atar fragmentation and the consequent conflicts and collective action problems without credible enforcement mechanisms to enforce those rights. Reliable enforcement of rules is one of the key features of Ostrom's institutional design principles for long enduring institutions governing the commons.

In the last 30 years, VIBA has tightened its enforcement mechanisms such as a stricter regulation on the transfer of work responsibilities to new members. A common rule adopted by the zangjeras requires that the sale of usufruct or cultivation rights or the employment of tenants would now require prior approval by the officers of the zangjera. Membership rules have been tightened with the screening of prospective members and prescribing mandatory membership seminars to ensure that new members imbibe the zangjera norms and understand their work obligations. In most cases, new members are also required to sign a contract affirming their recognition of the zangjera by-laws and the fines associated with non-conformance. These new formal requirements are now mandatory for all zangjeras before the transfer of cultivation rights or tenancy agreements are put into effect.

The increasing number of members, the fragmentation of atar shares, the need to mediate conflicts and monitor and enforce rule compliance as well as carry out other administrative tasks in the irrigation system has led to the creation of new positions of authority in the zangjera which were originally not prescribed in its early days. In the last 30 years, new positions of authority were created in VIBA, namely: (1) membership committee to screen and integrate new members; (2) by-laws committee to review and recommend changes to its by-laws as a response to changing circumstances; (3) education and program committee to ensure the continued training and education of the zangjera members; (4) complaint committee to handle complaints arising from noncompliance with rules and conflicts in water and land issues; (5) audit and inventory committee to deal with increasing financial transactions in the zangjera; and (6) administrator or maestro - the head of the family owning the atar share coordinates with all fractional holders of the atar share and is then held accountable for ensuring that the required contributions and obligations associated with a single atar share are fulfilled. In addition to having these new rules, the association also adopted a series of membership rules to regulate entry and exit in the association. These rules, which did not exist in 1980, now include approval by the Board of tenancy contracts, screening of prospective members and signing of contract by new members.

\subsection{Polycentricity}

The assignment of tradable land and water rights works as an adaptation mechanism for the zangjera because it was underpinned by a polycentric social order, i.e. diverse forms of self-organizing and overlapping social order, which facilitated a more efficient adaptation. First, there is a well functioning spot market for atar shares as well as long term markets for land, labor and water resources which allowed farmers to diversify their risks from flooding, drought, prices, soil quality and hence make them highly adaptive to vulnerabilities. Second, the zangjera itself as a cooperative society coordinates the activities of a large number of farmers and ensures the enforcement of rights and obligations in the atar based on customs along with formal agreements and low cost self enforcing regulations. Third, there also exists a federation mode of governance to deal with issues that commonly bind the nine zangjeras such as matters related to the operation and maintenance of the main dam and canal. Collectively, this polycentric social order provides the zangjera a structure to continuously adapt to climate vulnerabilities. Polycentricity is also one of the key institutional design principles suggested by Ostrom, which characterize robust institutions governing the commons. To summarize, the VIBA zangjera was faced with a number of climatic risks such as intense and frequent typhoons and associated flooding on one hand and intense and prolonged droughts on the other. The zangjera responded to these risks by introducing a range of risk mitigation measures such as: (1) introduction of atar property system to mitigate variability and ensure flexibility in labor mobilization, fairness in sharing of costs and benefits and are efficient/appropriate (low transaction cost, easily understood rules, appropriate for small, fragmented lands); (2) evolution of new property rights such as sale or lease of land or land rights, tenancy/sub-tenancy in response to economic and demographic pressures; (3) changing the valuation of the atar share in response to changes in the social, economic and ecological conditions; (4) construction of new dam to store water; (5) organization of the VIBA federation; (6) adjustment of cropping patterns; (7) adjustment of water distribution schedules; (8) introduction of lined canals to reduce seepage; (9) configuration of elongated land parcels and placing them perpendicular to water sources to diversity risk and allow more efficient use; and (10) creation of new positions to strengthen enforcement (membership, education, complaints and discipline committees).

\section{Conclusion}

In conclusion, I have argued that transaction cost is central to the analytics of climate adaptation and that the COW approach can provide foundations to this analytics. In particular, the Coase theorem on the tradability of rights serves as a foundation for the functioning of markets for land, water and labor. Williamson argued that transaction costs are a function of the governance mechanisms (i.e. contracts, firms and hierarchies) while Ostrom argued why and how a particular type of governance mechanism - cooperative societies in the commons governed by particular design principles - have lower transaction costs compared with alternative institutional designs such as state ownership and control.

I illustrated the COW model using the case of the zangjeras in the Philippines. The zangjeras are highly vulnerable to climate change compounded by economic, demographic and social vulnerabilities - but has managed to successfully apply market and collective action mechanisms - represented by 
the atar property system - under conditions of land and water scarcity and labor surplus. I argue that its success in adaptation overtime can be attributed to the following design principles: (1) clear allocation of rights and obligations; (2) fairness in the allocation of risks, costs and benefits; (3) reliance on prices and incentives as adaptation mechanisms; (4) adaptive efficiency, i.e. maximization welfare at least adaptation cost; (5) reliable enforcement mechanisms; and (6) a polycentric structure of governance. These findings are consistent with the literature on successful and long enduring collective action in the commons (Araral, 2009, 2011; Ostrom, 1990). Finally, these institutional design principles would have significant theoretical, practical and research implications for adaptation particularly for water resource management in a river basin context. This is because the issues that drive conflict and cooperation and hence adaptation in a river basin and irrigation context - credible commitment problems arising from asymmetric situations, uncertainty and high transaction costs and the ensuing incentive structure - are fundamentally similar although their scale is different. As $\mathrm{Wu}$ and Whittington (2006) conclude in a game theoretic paper on the Nile River, achieving incentive compatibility is central to finding cooperative solutions in situations faced with credible commitment problems. This paper has shown in the case of the VIBA zangjera an example of how incentive compatibility can be designed in practice - using markets and institutions for collective action - to lower transaction costs and solve these critical institutional problems for climate adaptation.

\section{REFERENCES}

Agrawal, A., 2002. Common resources and institutional sustainability. In: Ostrom, E., Dietz, T., Dolšak, N., Stern, P.C., Stonich, S., Weber, E.U. (Eds.), The Drama of the Commons. National Academy Press, Washington, DC.

Agrawal, A., 2007. The Role of Local Institutions to Climate Adaptation. Working Paper prepared for the World Bank, Washington, DC.

Araral, E., 2009. What explains collective action in the commons? Theory and evidence from the Philippines. World Development 37 (3), 687-697.

Arnell, N.W., 2004. Climate change and global water resources: SRES scenarios and socio-economic scenarios. Global Environmental Change 14, 31-52.

Baland, J., Plateau, J., 1996. Halting Degradation of Natural Resources: Is There is a Role for Rural communities? FAO, Rome.

Barnett, T.P., Malone, R., Pennell, W., Stammer, D., Semtner, B., Washington, W., 2004. The effects of climate change on water resources in the West: introduction and overview. Climatic Change 62, 1-11.

Berkes, F., 2012. Understanding uncertainty and reducing vulnerability: lessons from resilience thinking. In: Haque, C.E., Etkin, D. (Eds.), Disaster Risk and Vulnerability. McGillQueen's University Press, Montreal, pp. 27-44.

Coase, R., 1960. The problem of social cost. Journal of Law and Economics 1 (15), 8.
Coward, W., 1979. Principles of social organization in an indigenous irrigation system. Human Organization 38 (1), 28-36.

Eakin, H., 2005. Institutional change, climate risk, and rural vulnerability: cases from central Mexico. World Development 33 (11), 1923-1938.

Glaser, B.G., Strauss, A.L., 1967. The Discovery of Grounded Theory: Strategies for Qualitative Research. Aldine Publishing Company, Chicago.

Haque, C.E., Etkin, D., 2012. Dealing with disaster risk and vulnerability: people, community, and resilience perspectives. In: Haque, C.E., Etkin, D. (Eds.), Disaster Risk and Vulnerability. McGill-Queen's University Press, Montreal, pp. 3-23.

Howden, S., et al., 2007. Adapting agriculture to climate change. Proceedings of the National Academy of Sciences 104 (50), 1991-1996.

Janssen, M.A., 2011. Resilience and adaptation in the governance of social-ecological systems. International Journal of the Commons 5 (2), 340-512.

Kundzewicz, Z.W., Mata, L.J., Arnell, N., Döll, P., Kabat, P., Jiménez, B., Miller, K., Oki, T., Sen, Z., Shiklomanov, I., 2007. Freshwater resources and their management. In: Parry, M.L., Canziani, O.F., Palutikof, J.P., van der Linden, P.J., Hanson, C.E. (Eds.), Climate Change 2007: Impacts, Adaptation and Vulnerability. Contribution of Working Group II to the Fourth Assessment Report of the Intergovernmental Panel on Climate Change. Cambridge University Press, UK, pp. 173-210., http://www.ipcc.ch/pdf/ assessment-report/ar4/wg2/ar4-wg2-chapter3.pdf.

Lasco, R.D., Cruz, R.V.O., Pulhin, J.M., Pulhin, F.B., 2006. Tradeoff analysis of adaptation strategies for natural resources, water resources, and local institutions in the Philippines. AIACC Working Paper No. 32. International START Secretariat, Washington, DC.

Lehner, B., Döll, P., Alcamo, J., Henrichs, H., Kaspar, F., 2005. Estimating the impact of global change on flood and drought risks in Europe: a continental, integrated assessment. Climatic Change 75, 273-299.

Lejano, R., Ingram, H., 2009. Collaborative networks and new ways of knowing. Environmental Science and Policy 12, 653662.

PAGASA, 2011. Climate Change in the Philippines. Department of Science and Technology, Manila, Philippines. , http:// kidlat.pagasa.dost.gov.ph/cab/climate_change/main.html.

Pahl-Wostl, C., 2007. Transitions towards adaptive management of water facing climate and global change. Water Resources Management 21, 49-62.

Orlove, B., 2005. Human adaptation to climate change: a review of three historical cases and some general perspectives. Environmental Science and Policy 8, 589-600.

Ostrom, E., 1990. Governing the Commons: Institutions for Collective Action. Cambridge University Press, Cambridge, UK.

Ribot, J., 2002. Democratic Decentralization of Natural Resources. WRI, Washington DC.

Siy, R., 1980. Community Resource Management: Lessons from the Zangjera. University of the Philippines Press, Manila.

Stern, N., 2007. The Economics of Climate Change. Cambridge University Press, London.

Wade, R., 1989. Village Republics: Economic Conditions for Collective Action in South India. Cambridge University Press.

Wu, X., Whittington, D., 2006. Incentive compatibility and conflict resolution in international river basins: a case study of the Nile basin. Water Resources Research 42 (2). 